\title{
Influence of machining parameters on surface roughness and dry friction
}

\author{
Niraj Kumar and Punit Kumar*
}

Department of Mechanical Engineering, National Institute of Technology Kurukshetra, Haryana, India - 136119

\begin{tabular}{|c|c|}
\hline A R T I C L EI N F O & A B S T RACT \\
\hline $\begin{array}{l}\text { Article history: } \\
\text { Received } 6 \text { October, } 2015 \\
\text { Accepted } 7 \text { March } 2016 \\
\text { Available online } \\
8 \text { March } 2016 \\
\text { Keywords: } \\
\text { Surface roughness } \\
\text { Feed } \\
\text { Cutting speed } \\
\text { Friction }\end{array}$ & $\begin{array}{l}\text { Dry friction depends on the surface topography which, in turn, is governed by machining } \\
\text { parameters in addition to several other factors,. Therefore, in order to establish a qualitative } \\
\text { relationship among these factors, the surface roughness and coefficient of static friction are } \\
\text { measured for specimens machined on lathe and shaper machines with different values of } \\
\text { machining parameters. For the case of lathe, the measured Ra value is found to increase with } \\
\text { increase in feed rate and depth of cut, whereas, a marginal decrease is observed with increasing } \\
\text { spindle speed. Similar results with respect to cutting speed have been obtained for the case of } \\
\text { shaper machine. On the other hand, the coefficient of static friction, measured on steel substrate } \\
\text { using inclined plane method, is found to decrease with increasing Ra values for both the } \\
\text { specimen types. }\end{array}$ \\
\hline
\end{tabular}

(c) 2016 Growing Science Ltd. All rights reserved.

\section{Introduction}

Mechanical component involving rubbing action between mating surfaces are found extensively in all machines involving the transmission of power and/or motion. For longer service lives of such components, higher energy efficiency and smooth operation, it is necessary to minimize friction and wear. Therefore, it is important to understand the friction behavior of tribo-pairs and identify the various factors that influence the magnitude of friction. According to the classical theories of friction, the real area of contact is an important parameter and it is a function of surface roughness for a given set of material properties and loading condition. Surface roughness, in turn, is controlled primarily by the machining process parameters such as cutting speed, feed rate and depth of cut. Therefore, countless theoretical as well as experimental investigations pertaining to the aforesaid areas have been performed in the past. Some of the pertinent contributions are discussed in the following text.

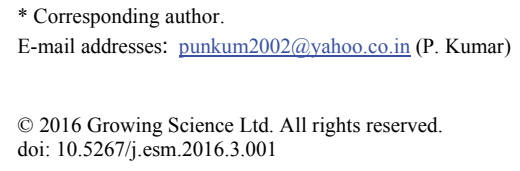


Sundaram and Lambert (1981) considered six machining parameters viz. feed rate, cutting speed, depth of cut, time of cut, nose radius and type of tool to monitor surface roughness. Selmy et al. (1989) studied the influence of surface roughness on different machining parameters such as spindle speed, feed rate and depth of cut. Lee and Ren (1996) studied friction, wear and lubrication of contacting bodies affected by surface roughness. Lou et al. (1999) reported significant increase in fatigue strength due to improvement of surface finish. Davim (2001) highlighted the importance of selecting an appropriate combination of cutting speed and feed rate to achieve a desired quality of surface finish. Suresh et al. (2002) concluded that genetic algorithms can be applied to determine minimum and maximum values of surface roughness and hence, optimum machining conditions. Feng and Wang (2002) reported that surface quality influenced the properties like wear resistance and friction of machined parts. Kirby et al. (2004) developed a model to predict surface roughness in turning operation. Ozel et al. (2007) reported significant enhancement in tool life for the case of low feed rate along with low cutting speed. Lan et al. (2008) considered four cutting parameters viz. feed rate, cutting speed, depth of cut and nose runoff varied in three levels for predicting the surface roughness of CNC turned components. Thamma (2008) reported improved surface finish at high cutting speed, low feed rate and small nose radius. Fnides et al. (2008) found that feed rate and flank wear had a great influence on surface roughness. Korkut and Donerats (2007) studied the effect of feed rate and cutting speed on the cutting force, surface roughness and tool chip contact length. Lalwani et al. (2008) reported negligible effect of cutting speed on surface roughness and cutting forces. Silva et al. (2008) reported a reduction in the specific cutting force with an increase in cutting speed. Moreover, the surface finish was found to be significantly affected by cutting speed - tending to deteriorate with increasing speed. Abdullah et al. (2008) performed end milling operation on aluminum platen and found surface roughness to be governed predominantly by feed rate. Reddy et al. (2011) and Rodrigues et al. (2012) also found the effect of feed rate on surface roughness to be highly pronounced. While depth of cut had a noteworthy influence on cutting force, its effect on surface roughness was quite insignificant. Kumar et al. (2012) investigated the effect of spindle speed and feed rate on surface roughness while turning carbon alloy steel specimens on a CNC lathe. The five different alloy carbon steels used for turning were SAE 8620, EN8, EN19, EN24 and EN47. It was observed that surface roughness increased with increase in feed rate and decrease in cutting speed. Das et al. (2013) and Vipindas (2013) reconfirmed that feed rate affects surface roughness to the greatest extent.

A few studies pertaining to the effect of surface condition on friction are also available in literature. For instance, Koura (1980) investigated the effect of surface texture on friction mechanism using a universal testing machine. Steel specimens were prepared with different degrees of roughness by grinding, lapping and polishing. The results showed that the surfaces and friction characteristics during sliding were functions of the degree of roughness Xiao et al. (2003) reported that surface roughness significantly influenced friction under some specific running conditions.

The foregoing discussion reveals that the issues related to machining process and friction have been addressed in an isolated manner without recognizing the underlying interrelationships. However, as the prediction of friction still remains a major challenge, it is required to adopt an integrated perspective so as to develop a proper understanding of the issues related to friction and its prediction. Furthermore, experimental study of dry friction behavior with respect to surface roughness has not received adequate attention.

In view of the aforesaid facts, the present study aims at demonstrating the interrelationship between machining parameters, surface roughness and static friction. This work is intended to be useful for the development of an integrated and systematic approach to predict and/or control friction. To serve these objectives, engineering surfaces with different levels of surface roughness are obtained by turning and shaping mild steel specimens at different values of machining parameters. The coefficient of friction for each specimen is measured and conclusions are drawn in the light of the results so obtained. 


\section{Experimental set up and measuring instrument}

The experiments are performed on lathe machine. A high-speed-steel tool is used for machining mild steel specimens round in shape. The lathe parameters viz., spindle speed, feed rate and depth of cut are varied within the ranges specified in Table 1 so as to study the effect on surface roughness and static friction. A high precision and heavy duty shaper machine is also used for other experiments. A single point cutting tool is used for machining in shaper machine. Several batches of workpices have been machined on shaper at different values of shaper speed and depth of cut as given Table 2.

Table 1. Lathe machine input parameters, symbol and range

\begin{tabular}{lcc}
\hline Input parameter & Symbol & Range \\
\hline Spindle speed & $s$ & $325-500 \mathrm{rpm}$ \\
Feed rate & $f$ & $0.04-0.16 \mathrm{~mm} / \mathrm{rev}$ \\
Depth of cut & $d$ & $0.4-1.2 \mathrm{~mm}$ \\
\hline
\end{tabular}

Table 2. Shaper machine input parameters, symbol and range

\begin{tabular}{lll}
\hline Input parameter & Symbol & Range \\
\hline Shaper speed & $\mathrm{s}$ & 12,19 and 37 stroke $/ \mathrm{min}$ \\
Depth of cut & $\mathrm{d}$ & $1.0 \mathrm{~mm}$ \\
\hline
\end{tabular}

The instrument used here for measurement of surface roughness is Surfcom Flex 50 A depicted in Fig. 1. The specimen is attached to the detector unit of the Surfcom Flex 50 A, which traces the irregularities of the specimen surface and displays the surface profile on a screen. Some of the salient specifications of this instrument are listed in Table 3.

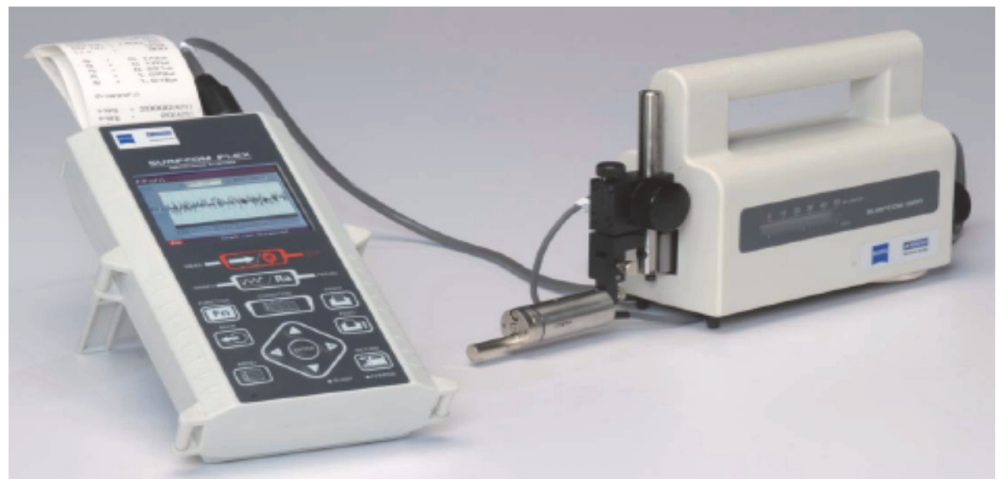

Fig. 1. Surface roughness tester.

Table 3. Specification of Surfcom Flex 50 A

\begin{tabular}{ll}
\hline Parameters & Specification \\
\hline Measuring range & $50 \mathrm{~mm}$ \\
Maximum measuring force & $0.75 \mathrm{mN}$ \\
Stylus material & Diamond \\
Stylus tip radius & $2 \mu \mathrm{m}$ \\
Power source & Built- in rechargeable battery \\
\hline
\end{tabular}

\section{Effect of machining parameters on surface roughness}

Mild steel specimens are turned on a lathe using HSS single point cutting tool for eight combinations of spindle speed $(s)$, depth of cut $(d)$ and feed rate $(f)$. Machining has also been performed on a shaper machine at three different values of cuttig speesd $(s)$. The surface roughness of all the workpieces is measured using diamond-tipped stylus profilometer and the corresponding $\mathrm{R}_{\mathrm{a}}$ values are listed in Tables 4 and 5 for lathe and shaper machines, respectivelly. 
Table 4. Measured $\mathrm{R}_{\mathrm{a}}$ values for different combinations of turning parameters

\begin{tabular}{cccc}
\hline Spindle speed $(\mathrm{rev} / \mathrm{min})$ & Depth of cut $(\mathrm{mm})$ & Feed rate $(\mathrm{mm} / \mathrm{rev})$ & $\mathrm{R}_{\mathrm{a}}(\mu \mathrm{m})$ \\
\hline \multirow{3}{*}{325} & 0.4 & 0.04 & 2.615 \\
& & 0.16 & 6.404 \\
\cline { 2 - 4 } & \multirow{2}{*}{1.2} & 0.04 & 3.938 \\
& & 0.4 & 10.179 \\
\hline \multirow{3}{*}{550} & \multirow{2}{*}{0.4} & 0.04 & 2.306 \\
& \multirow{2}{*}{1.2} & 0.16 & 4.539 \\
\hline & & 0.04 & 2.559 \\
& & 0.4 & 8.321 \\
\hline
\end{tabular}

Table 5. Measured $R_{a}$ values for different cutting speeds on shaper

\begin{tabular}{ccc}
\hline Cutting speed (stroke/min) & Depth of cut $(\mathrm{mm})$ & $\mathrm{R}_{\mathrm{a}}(\mu \mathrm{m})$ \\
\hline 12 & & 6.725 \\
19 & 1.0 & 6.379 \\
37 & & 5.774 \\
\hline
\end{tabular}

The measured surface roughness profiles are shown from Fig. 2 Fig. 4. It can be seen that under the present conditions, the $R_{a}$ value decreases with increasing cutting speed, whereas, an increase in $R_{a}$ value is observed with increase in depth of cut and feed rate. However, the effect of feed rate on surface roughness is the most pronounced as reported in literature. For the case of specimens machined on lathe, if $\mathrm{R}_{\mathrm{a}}$ is assumed proportional to $f^{a}$, the exponent $a$ is found to vary between 0.41 and 0.65 under the present conditions, whereas, the exponents pertaining to $s$ and $d$ are much smaller. For the case of specimens machined on shaper, $\mathrm{R}_{\mathrm{a} \infty s^{-b}}$, where $b$ ranges between 0.11 and 0.14 .

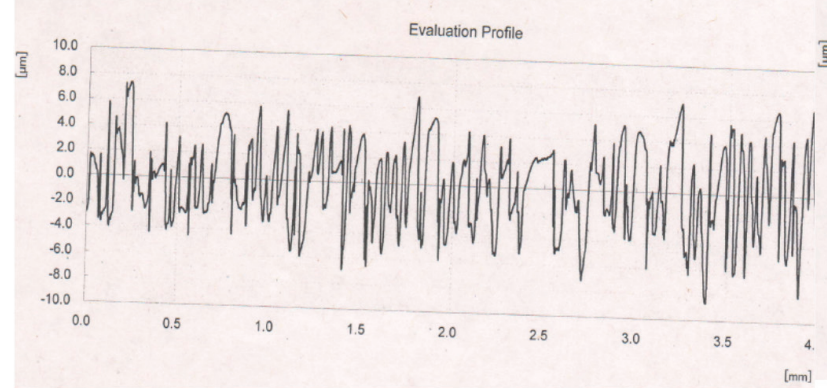

(a) $d=0.4 \mathrm{~mm}, f=0.04 \mathrm{~mm} / \mathrm{rev}$

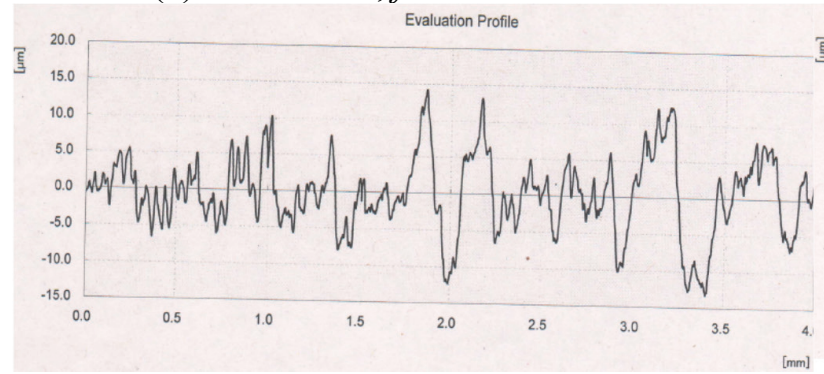

(c) $d=1.2 \mathrm{~mm}, f=0.04 \mathrm{~mm} / \mathrm{rev}$

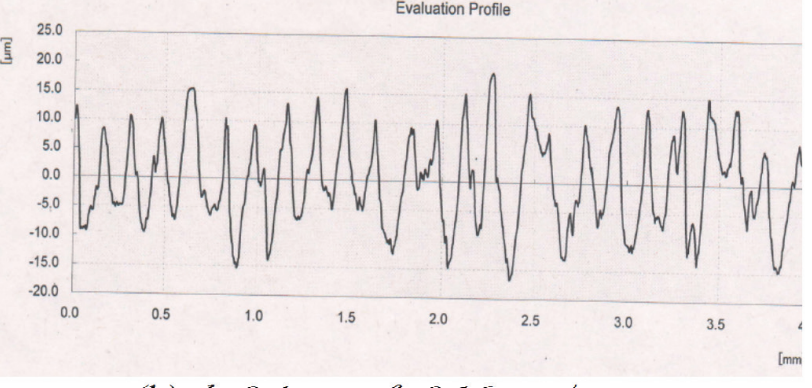

(b) $d=0.4 \mathrm{~mm}, f=0.16 \mathrm{~mm} / \mathrm{rev}$

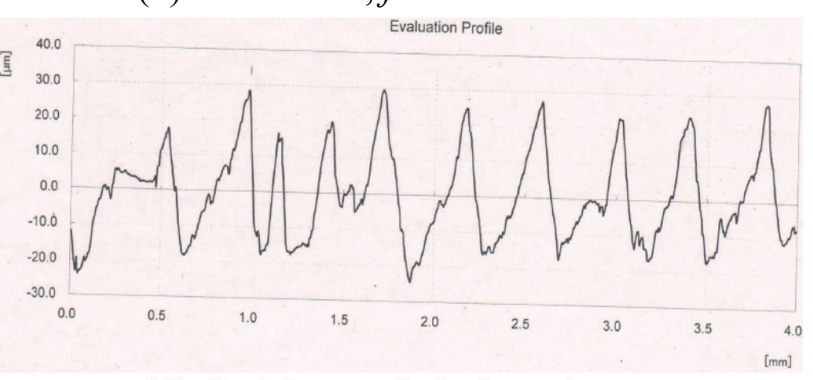

(d) $d^{\prime}=1.2 \mathrm{~mm}, f=0.4 \mathrm{~mm} / \mathrm{rev}$

Fig. 2. Measured surface roughness profiles for specimens turned at $s=325 \mathrm{rev} / \mathrm{min}$ 


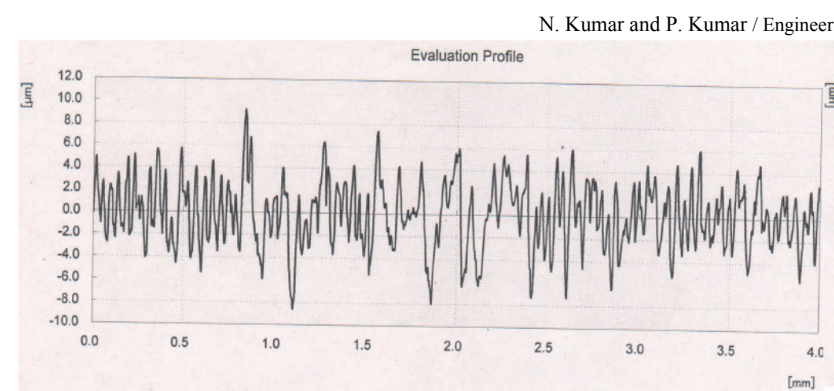

(a) $d=0.4 \mathrm{~mm}, f=0.04 \mathrm{~mm} / \mathrm{rev}$

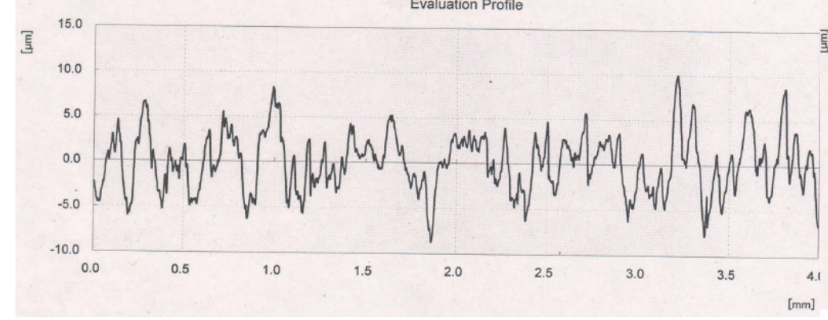

(c) $d=1.2 \mathrm{~mm}, f=0.04 \mathrm{~mm} / \mathrm{rev}$

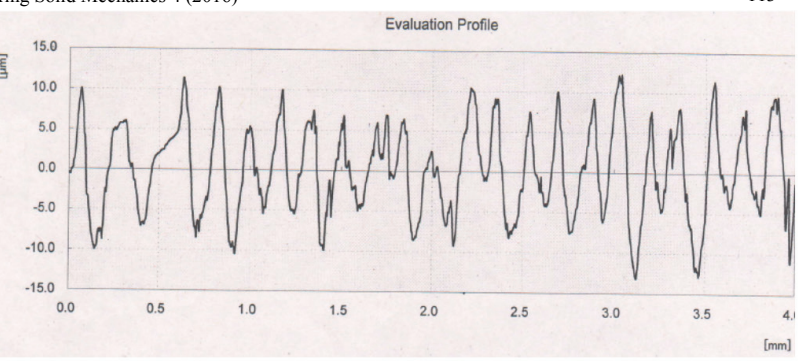

(b) $d=0.4 \mathrm{~mm}, f^{\prime}=0.16 \mathrm{~mm} / \mathrm{rev}$

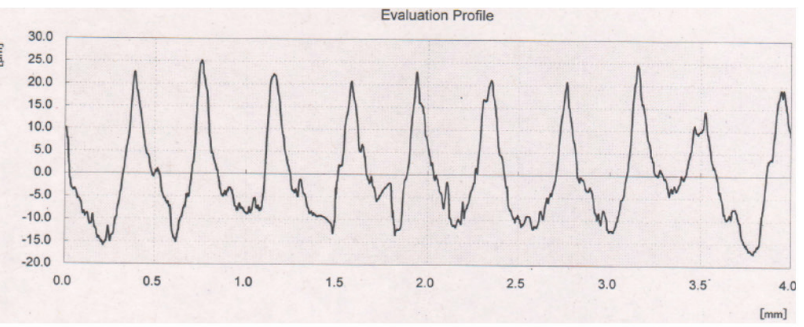

(d) $d=1.2 \mathrm{~mm}, f=0.4 \mathrm{~mm} / \mathrm{rev}$

Fig. 3. Measured surface roughness profiles for specimens turned at $s=550 \mathrm{rev} / \mathrm{min}$

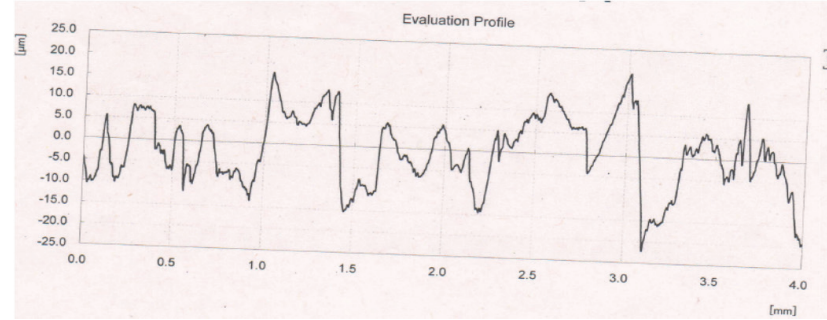

(a) $s=12$ strokes $/ \mathrm{min}$

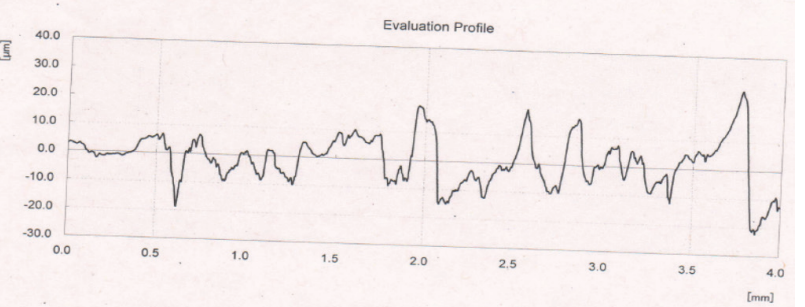

(b) $s=19$ strokes $/ \mathrm{min}$

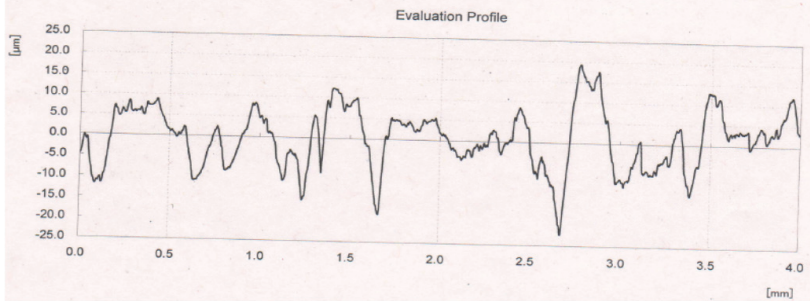

(c) $s=37$ strokes/min

Fig. 4. Measured surface roughness profiles for specimens machined on shaper

\section{Effect of machining parameters on static friction coefficient}

In order to investigate the effect of surface roughness and hence, machining parameters on dry firction behavior, the coefficient of static friction $(\mu)$ is measured for each specimen using inclined plane method with steel substrate. Figs. 5(a-d) compare the values of $\mu$ at two different feed rates for four combinations of spindle speed and depth of cut. It is quite apparent from these figures that the coefficient of friction decreases noticeably with increase in feed rate. Besides, $\mu$ is found to decrease slightly with increase in depth of cut, whereas, a marginal increase is observed with increase in spindle sppeed. Similarly, Fig. 6 compares the coefficient of friction pertaining to the specimens machined on shaper at three different cutting speesds. Clearly, it can be seen that the coefficient of static friction increases with increasing cutting speed. 


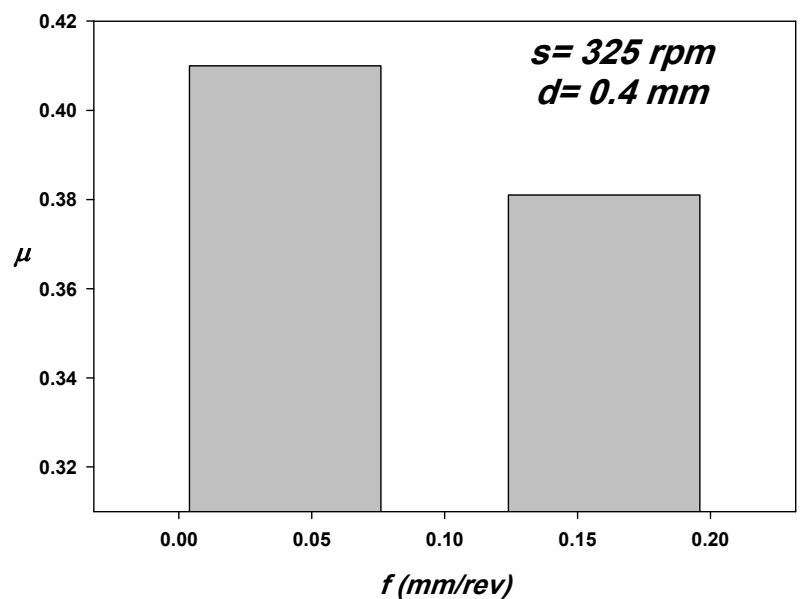

(a)

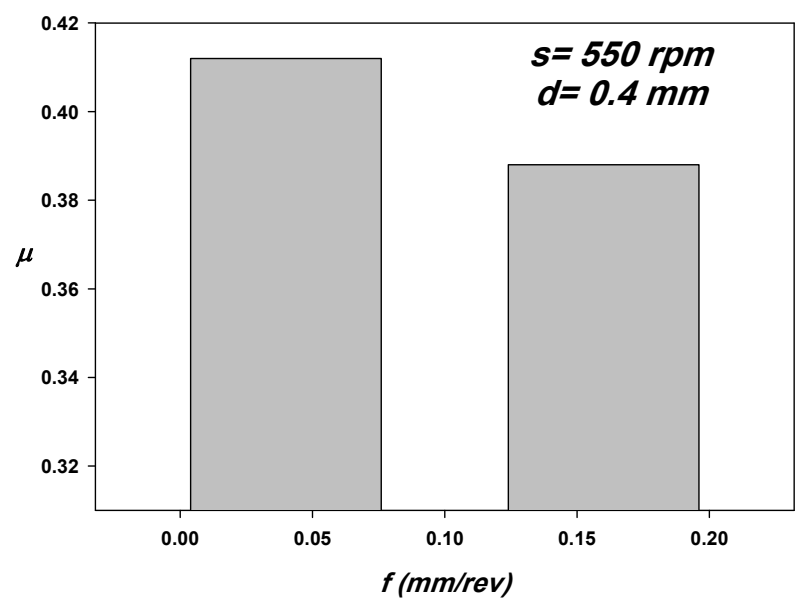

(c)

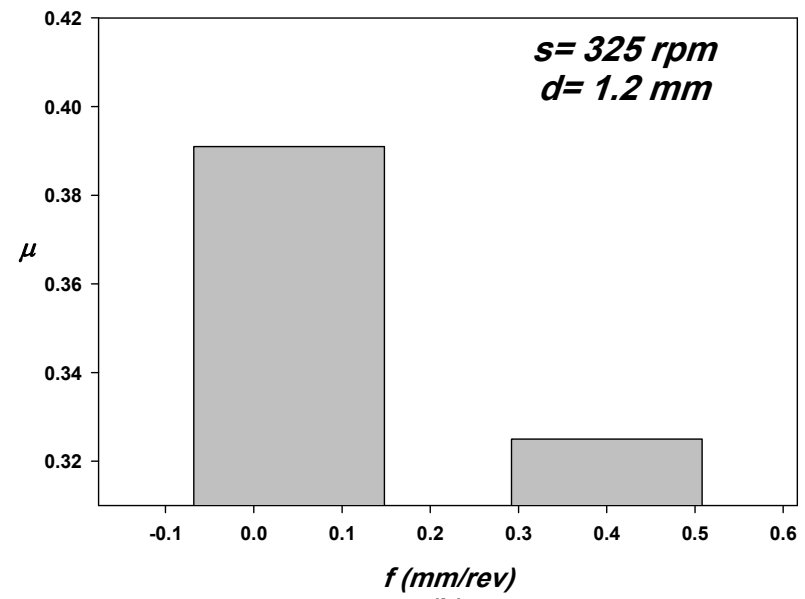

(b)

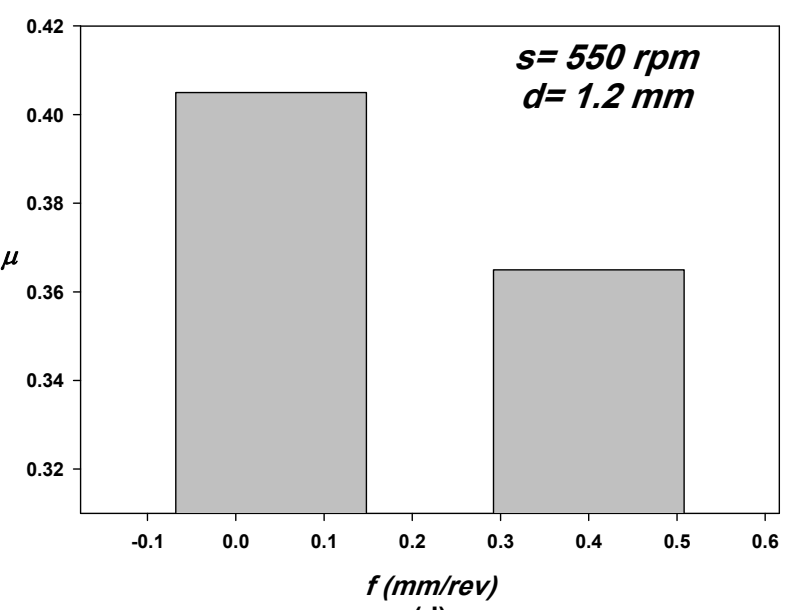

(d)

Fig. 5. Comparison of measured friction behavior for specimens machined on lathe at different feed rates

These observations clearly indicate the dependence of static friction on surface roughness. For better visualization,
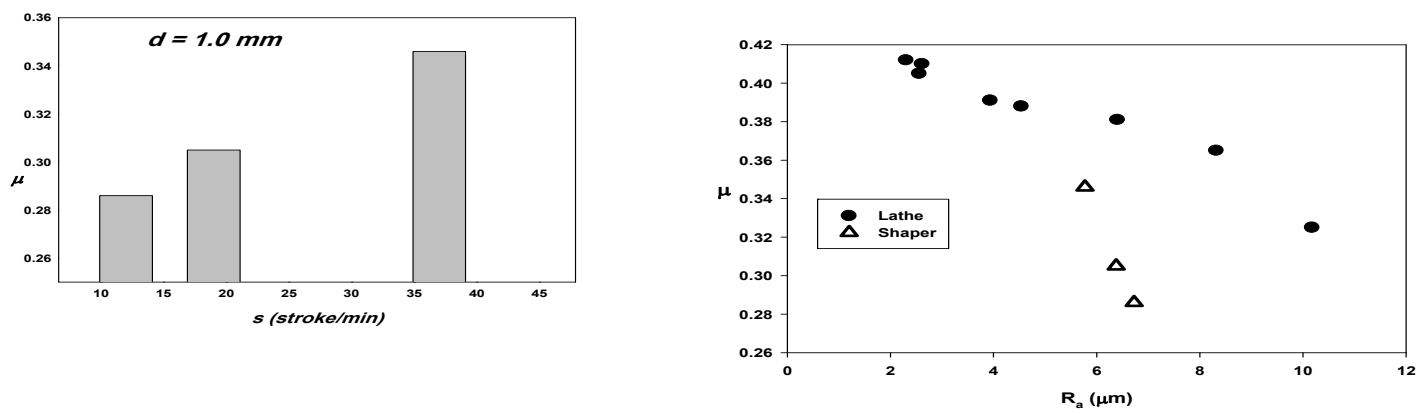

Fig. 6. Comparison of measured friction behavior for specimens machined on shaper at different

Fig. 7. Correlation between measured static cutting speeds

Fig. 7 plots the $\mu$ values against the corresponding $\mathrm{R}_{\mathrm{a}}$ values for both the types of specimens considere here. It is quite apparnt from Figure that there is a negative $\mu$ correlation between coefficient of friction and $R_{a}$ values. Hence, it may be stated that static friction increases as the surface becomes 
smoother under the present conditions. This is in consonance with the adhesion theory of friction. According to this theory, adhesion occurs between the contacting surfaces and junctions are formed at the high spots. Friction is the force required to tear-off these junctions and initiate sliding. Therefore, if the surfaces are perfectly smooth, the adhesion will be the strongest and hence, firction will be maximum. Now, in order to demonstrate that the coefficient of friction can be expressed as a function of the milling process parameters, the following equation has been derived using $2^{3}$ factorial approach: Equation for lathe machine parameters

$$
\begin{aligned}
\mu= & 0.3814-0.0099 D-0.0253 F+0.0021 S \\
& -0.0012 D F+0.0114 D S-0.0041 F S+0.0106 D F S
\end{aligned}
$$

where

$$
D=\frac{d-\left(\frac{d_{1}+d_{2}}{2}\right)}{\left(\frac{d_{2}-d_{1}}{2}\right)}, \quad F=\frac{f-\left(\frac{f_{1}+f_{2}}{2}\right)}{\left(\frac{f_{2}-f_{1}}{2}\right)}, S=\frac{s-\left(\frac{s_{1}+s_{2}}{2}\right)}{\left(\frac{s_{2}-s_{1}}{2}\right)}
$$

$s_{1}, f_{1}, d_{1}$ are the minimum values of cutting speed, feed and depth of cut used in this paper.

$s_{2}, f_{2}, d_{2}$ are the maximum values of cutting speed, feed and depth of cut used in this paper.

It can be seen that the magnitude of the coefficient of $F$ is greater than those of $D$ and $S$. This reconfirms the dominance of feed rate over the other two machining parameters.

Equation for shaper machine parameters

$$
S=420.24 \mu-108.58
$$

where $S=$ Stroke/min.

\section{Conclusions}

Mild steel specimens have been machined on lathe and shaper machines with different values of machining parameters and surface roughness is measured using stylus profilometer. For the case of specimens machined on lathe, the measured $R_{a}$ value was found to increase with increase in feed rate and depth of cut, whereas, a marginal decrease is observed with increasing spindle speed. However, the influence of feed rate was found to be the most pronounced. For the specimens machined on shaper, an increase in cutting speed is found to cause noticeable reduction in the measured $R_{a}$ value. Furthermore, the coefficient of static friction was measured on steel substrate using inclined plane method. These measurements clearly show a strong negative correlation between the coefficient of friction and $R_{a}$ values for all three cases considered herein. Hence, it has been demonstrated that machining parameters can be carefully controlled so as to achieve a desired level of surface roughness and also to restrict friction within desired limits. This work is intended to act as a precursor to further research aimed at investigating the finer aspects of surface roughness profile that affect dry friction.

\section{References}

Abdullah, A. B., Chia, L. Y., \& Samad, Z. (2010). The effect of feed rate and cutting speed to surface roughness. Asian Journal of Scientific Research, 3(4), 278-287.

Das, S. R., Kumar, A., \& Dhupal, D. (2013). Effect of machining parameters on surface roughness in machining of hardened aisi 4340 steel using coated carbide inserts. International Journal of Innovation and Applied Studies, 2(4), 445-453.

Davim, J. P. (2001). A note on the determination of optimal cutting conditions for surface finish obtained in turning using design of experiments. Journal of Materials Processing Technology, 116(2), 305-308. 
Fnides, B., Aouici, H., \& Yallese, M. A. (2008). Cutting forces and surface roughness in hard turning of hot work steel X38CrMoV5-1 using mixed ceramic. Mechanika, 2(70), 73-78.

Kirby, E. D., Zhang, Z., \& Chen, J. C. (2004). Development of an accelerometer-based surface roughness prediction system in turning operations using multiple regression techniques. Journal of Industrial Technology, 20(4), 1-8.

Korkut, I., \& Donertas, M. A. (2007). The influence of feed rate and cutting speed on the cutting forces, surface roughness and tool-chip contact length during face milling. Materials \& Design, 28(1), 308312.

Koura, M. M. (1980). The effect of surface texture on friction mechanisms. Wear, 63(1), 1-12.

Kumar, N. S., Shetty, A., Shetty, A., Ananth, K., \& Shetty, H. (2012). Effect of spindle speed and feed rate on surface roughness of Carbon Steels in CNC turning. Procedia Engineering, 38, 691-697.

Lalwani, D. I., Mehta, N. K., \& Jain, P. K. (2008). Experimental investigations of cutting parameters influence on cutting forces and surface roughness in finish hard turning of MDN250 steel. Journal of Materials Processing Technology, 206(1), 167-179.

Lan, T. S., Lo, C. Y., Wang, M. Y., \& Yen, A. Y. (2008). Multi quality prediction model of cnc turning using back propagation network. Information Technology Journal, 7(6), 911-917.

Lee, S. C., \& Ren, N. (1996). Behavior of elastic-plastic rough surface contacts as affected by surface topography, load, and material hardness. Tribology Transactions, 39(1), 67-74.

Lou, M. S., Chen, J. C., \& Li, C. M. (1998). Surface roughness prediction technique for CNC endmilling. Journal of Industrial Technology, 15(1), 1-6.

Özel, T., Karpat, Y., Figueira, L., \& Davim, J. P. (2007). Modelling of surface finish and tool flank wear in turning of AISI D2 steel with ceramic wiper inserts. Journal of Materials Processing Technology, 189(1), 192-198.

Reddy, M. R., Kumar, P. R., \& Rao, G. K. M. (2011). Effect of feed rate on the generation of surface roughness in turning. International Journal of Engineering Science and Technology (IJEST), 3(11).

Rodrigues, L. L., Kantharaj, A. N., Kantharaj, B., Freitas, W. R. C., \& Murthy, B. R. N. (2012). Effect of cutting parameters on surface roughness and cutting force in turning mild steel. Research Journal of Recent Sciences, 1(10), 19-26.

Selmy, A. I., El-Sonbaty, I., Shehata, F., \& Khashaba, U. A. (1989). Some factors affecting the accuracy of turned parts. Scientific Bulletin of the Faculty of Engineering, 24(2), 356-368.

Silva, L. R., Abrao, A. M., Rubio, J. C., \& Davim, J. P. (2008). A Note on the Influence of Cutting Speed on Cutting Forces and Surface Finish During Precision Turning of AISI 1045 Steel. Annals of Faculty of Engineering Hunedoara-International Journal of Engineering, 113-118.

Suresh, P. V. S., Rao, P. V., \& Deshmukh, S. G. (2002). A genetic algorithmic approach for optimization of surface roughness prediction model. International Journal of Machine Tools and Manufacture, 42(6), 675-680.

Sundaram, R. M., \& Lambert, B. K. (1981). Mathematical models to predict surface finish in fine turning of steel. Part I. The International Journal of Production Research, 19(5), 547-556.

Thamma, R. (2008). Comparison between multiple regression models to study effect of turning parameters on the surface roughness. In Proceedings of the 2008 IAJC-JME International Conference ISBN (pp. 978-1).

Vipindas, M. P. (2013). Dr. Govindan P,“Taguchi-Based Optimization of Surface Roughness in CNC Turning Operation”. International Journal of Latest Trends in Engineering and Technology, 2(4), 454-463.

Wang, X., \& Feng, C. X. (2002). Development of empirical models for surface roughness prediction in finish turning. The International Journal of Advanced Manufacturing Technology, 20(5), 348356.

Xiao, L., Rosen, B. G., Amini, N., \& Nilsson, P. H. (2003). A study on the effect of surface topography on rough friction in roller contact. Wear, 254(11), 1162-1169. 